\title{
Comment on "Seasonal variation of clinical characteristics and prognostic of adult patients admitted to an intensive care unit"
}

\author{
Guijun Xu1 (1), Xiaofei Li ${ }^{2 * ~(1) ~}$
}

Dear Editor,

We were lucky enough to read the study by Galvão et al. ${ }^{1}$ in which they demonstrated that summer months presented a higher proportion of clinical and emergency surgery patients with higher mortality rates and sepsis at intensive care unit admission did not show seasonal behavior. This study shows us the year pattern of emergency surgery, which is of great reference value for disease prevention and treatment. However, some concerns should be raised in my opinion.

To begin with, there are many reasons for the higher mortality rates of adult patients admitted to an intensive care unit. The researchers did not analyze the annual data because it was not easy to see regularity when all the years were analyzed together. The author does not define the four seasons in the method section, because different countries have different understandings of the four seasons. To sum up, the author believes that the annual separate analysis, to find out the specific months of emergency cases will reach a peak.

In addition, Figure 4 found that the highest number of emergency cases occurred in 2014-2015, while the number of emergency cases decreased year by year, which is not related to local health service policies. Diagnostic levels, data integrity, and health policies all affect the relationship between the number of emergency cases and the month.

\section{AUTHORS “CONTRIBUTIONS}

All authors have contributed equal to work.

\section{REFERENCE}

1. Galvão G, Mezzaroba AL, Morakami F, Capeletti M, Franco Filho O, Tanita M, et al. Seasonal variation of clinical characteristics and prognostic of adult patients admitted to an intensive care unit. Rev Assoc Med Bras (1992). 2019;65(11):1374-83. https://doi. org/10.1590/1806-9282.65.11.1374

'Yiwu Central Hospital, Department of Nephrology - Zhejiang, China.

${ }^{2}$ Yiwu Central Hospital, Department of Infectious Diseases - Zhejing, China.

*Corresponding author: xiaofeili2000@163.com

Conflicts of interest: the authors declare there is no conflicts of interest. Funding: none.

Received on February 04, 2021. Accepted on March 14, 2021. 